\title{
Characterization of the vasodilatory action of testosterone in the human pulmonary circulation
}

\author{
Alyson M Smith' \\ Robert T Bennett ${ }^{2}$ \\ T Hugh Jones' \\ Mike E Cowen ${ }^{2}$ \\ Kevin S Channer ${ }^{3}$ \\ Richard D Jones'
}

'Academic Unit of Diabetes, Endocrinology and Metabolism, The University of Sheffield, Sheffield, UK; ${ }^{2}$ Department of Cardiothoracic Surgery, Castle Hill Hospital, Hull and East Yorkshire Hospitals NHS Trust, Cottingham, UK; ${ }^{3}$ Department of Cardiology, Royal Hallamshire Hospital, Sheffield, UK
Correspondence: Kevin S Channer MI 3I, Cardiology, Royal Hallamshire Hospital, Glossop Road, Sheffield SIO 2JF, United Kingdom

Tel +44 II 4 27I 3473

Fax +44 II 4 27। 2042

Email kevin.channer@sth.nhs.uk

\begin{abstract}
Aim: To assess for the first time the vasodilatory effect of testosterone in the human pulmonary circulation utilizing both isolated human pulmonary arteries and isolated perfused human lungs. In addition, a secondary aim was to determine whether there was any difference in the response to testosterone dependant upon gender.

Methods: Isolated human pulmonary arteries were studied by wire myography. Vessels were preconstricted with $\mathrm{U} 46619(1 \mathrm{nM}-1 \mu \mathrm{M})$ prior to exposing them to either testosterone $(1 \mathrm{nM}-100 \mu \mathrm{M})$ or ethanol vehicle $(<0.1 \%)$. Isolated lungs were studied in a ventilated and perfused model. They were exposed to $\mathrm{KCl}(100 \mathrm{mM})$, prior to the addition of either testosterone $(1 \mathrm{nM}-100 \mu \mathrm{M})$ or ethanol vehicle $(<0.1 \%)$.

Results: Testosterone caused significant vasodilatation in all preparations, but a greater response to testosterone was observed in the isolated perfused lungs, $24.9 \pm 2.2 \%$ at the $100 \mu \mathrm{M}$ dose of testosterone in the isolated pulmonary arteries compared to $100 \pm 13.6 \%$ at the $100 \mu \mathrm{M}$ dose in the isolated perfused lungs. No significant differences in the response to testosterone were observed between sexes.

Conclusion: Testosterone is an efficacious vasodilator in the human pulmonary vasculature and this is not modulated by patient sex. This vasodilator action suggests that testosterone therapy may be beneficial to male patients with pulmonary arterial hypertension.
\end{abstract}

Keywords: human, pulmonary circulation, pulmonary hypertension, sex hormone, testosterone, vasodilation

\section{Introduction}

Sex hormones exert their biological effects primarily through genomic mechanisms. However both female and male sex hormones also elicit nongenomic effects. Estrogens such as $17 \beta$-estradiol act as vasodilators through the release of nitric oxide from the vascular endothelium and also by relaxing vascular smooth muscle cells directly (Gonzales et al 2001). In contrast, testosterone and progesterone have no endothelial effects in vitro, but have been shown to cause vasodilatation by direct interaction with ion channels within the vascular smooth muscle cell membrane (Li et al 2001; Jones et al 2002). In this respect we have recently reported that testosterone acts like the calcium channel blocker nifedipine by inhibiting the L-type voltage-gated calcium channels (VGCCs) (Scragg et al 2004; Hall et al 2006). Clinical trials in patients have shown that testosterone prolongs the time to myocardial ischemia in patients with chronic stable angina (English et al 2000a) and improves exercise capacity in men with heart failure (Pugh et al 2004), effects which may be a consequence of vasodilatation induced by this cellular action.

In the pulmonary circulation, pulmonary arterial hypertension $(\mathrm{PAH})$ of which idiopathic pulmonary hypertension is a subgroup, previously known as primary pulmonary hypertension, is three times more common in females compared with males (Dalonzo et al 1991). PAH is a rare disease of the pulmonary vasculature 
defined as a mean pulmonary artery pressure $>25 \mathrm{mmHg}$ at rest or $30 \mathrm{mmHg}$ with exercise (Gibbs et al 2001). The pathogenesis of the development of PAH is proposed to be multifactorial, involving genetic factors such as the transforming growth factor beta (TGF- $\beta$ ) superfamily of genes, vasoactive mediators such as prostacyclin, nitric oxide (NO), serotonin, angiotensin II and endothelin 1 (ET-1), as well as cytokines and other growth factors such as vascular endothelial growth factor (VEGF) (reviewed in Runo and Loyd 2003). These conspire to induce vascular remodeling and vasoconstriction and the characteristic pathological changes, including medial hypertrophy of the muscular pulmonary arteries, concentric laminar intimal fibrosis, plexiform lesions, fibrinoid degeneration and thrombotic lesions (Wagenvoort 1980; Bjornsson and Edwards 1985; Pietra et al 1989).

Testosterone has been shown to induce vasodilatation in the rat pulmonary vasculature (English et al 2001; Jones et al 2002), with a mechanism proposed to involve a calcium antagonist action (Jones et al 2002). This study was therefore carried out to assess for the first time, the effects of testosterone in the human pulmonary circulation utilizing both isolated human pulmonary arteries and isolated perfused human lungs. In addition, a secondary aim was to determine whether there was any difference in the response to testosterone between males and females.

\section{Methods}

This study was carried out in accordance with the declaration of Helsinki (2000) of the World Medical Association and full approval to undertake the study was obtained from the relevant local ethics committee. All patients gave written informed consent. Lung samples were obtained from patients ( $n=25$, age $=62[3]$ years $)$ undergoing elective lobe or lung resection at Northern General Hospital, Sheffield and Castle Hill Hospital, Hull.

\section{Isolated human pulmonary arteries}

Intralobar pulmonary arteries were carefully dissected from healthy areas of lung sections obtained from male $(n=7$ age $=65$ [3] years) and female patients $(n=6$, age $=56$ [7] years $)$. Care was taken to avoid damage to the vessels' smooth muscle layer or endothelium. Vessels were then mounted on two $40 \mu \mathrm{m}$ stainless steel wires between the jaws of an automated small vessel myograph (Cambustion Ltd, Cambridge, UK). The myograph bath contained $7 \mathrm{ml}$ physiological saline solution (PSS) warmed to $37{ }^{\circ} \mathrm{C}$ and bubbled with $95 \% \mathrm{O}_{2} / 5 \%$ $\mathrm{CO}_{2}$ to maintain a $\mathrm{pH}$ of 7.4. Vessels were then loaded to a tension equivalent to a transmural pressure of $17.5 \mathrm{mmHg}$, the normal in vivo pressure.

After loading, the intralobar pulmonary arteries $(\mathrm{n}=32$, mean internal diameter $=546[45] \mu \mathrm{m})$ studied in the Cambustion myograph were then allowed to equilibrate before exposure to $1 \mu \mathrm{M}$ U46619. U46619 is a prostaglandin analogue, acting at VGCCs and store operated calcium channels (SOCCs), causing vasoconstriction. The maximum contraction was then recorded before the addition of ACh $(1 \mu \mathrm{M})$, which causes endothelium dependant vasodilatation. Endothelial integrity was confirmed by $>10 \%$ vasodilatation response to $\mathrm{ACh}$. The vessels were then washed by changing the PSS and left to re-equilibrate back to their original baseline tension. Vessels were then exposed to cumulative doses of U46619 (1 nM-1 $\mu \mathrm{M})$ and after reaching maximum contraction they were exposed to either cumulative doses of testosterone $(1 \mathrm{nM}-100 \mu \mathrm{M})$ or ethanol vehicle (maximum concentration $=0.1 \%$ ). The addition of ethanol vehicle was carried out to ensure that the ethanol itself, in which the testosterone is dissolved, did not cause vasodilatation.

After a maximal dilatation had been observed vessels were washed by changing the PSS in the myograph bath and allowed to return to baseline tension. The vessels were subsequently exposed to cumulative doses of U46619 (1 nM-1 $\mu \mathrm{M})$, and cumulative concentrations of the alternative agent, either ethanol vehicle or testosterone.

\section{Isolated perfused human lung model}

The ex vivo saline perfused human lung system (Bennett et al 2004) is shown in Figure 1. Lung samples $(n=12)$ were obtained from male $(\mathrm{n}=6$, age $=62$ [7] years) and female $(n=6$, age $=66[4]$ years $)$ patients and suspended from a force transducer (strain gauge) inside the collection reservoir (Sorin Biomedica, Quedgeley, Gloucester, UK). The pulmonary arterial and bronchial circulations were cannulated using the largest cannulae possible. The bronchial cannula was connected to a piston ventilator (Harvard Apparatus Ltd, Edenbridge, Kent, UK) and was ventilated with room air at 10 breaths $/ \mathrm{min}$ and tidal volume 100-300 $\mathrm{ml}$. The pulmonary artery cannula was connected to a perfusion circuit (Cobe Laboratories, Quedgeley, Gloucester, UK) which had been primed with 1 liter oxygenated Krebs bicarbonate solution. The perfusate was circulated to the pulmonary arteries from a second reservoir (Baxter Healthcare, Compton, Berkshire, UK) via a peristaltic roller pump 100-300 ml/min (Terumo UK, Knowsley, Merseyside, UK). The temperature was maintained at $36-38^{\circ} \mathrm{C}$ by a heat exchanger (Sorin Biomedica, California, 


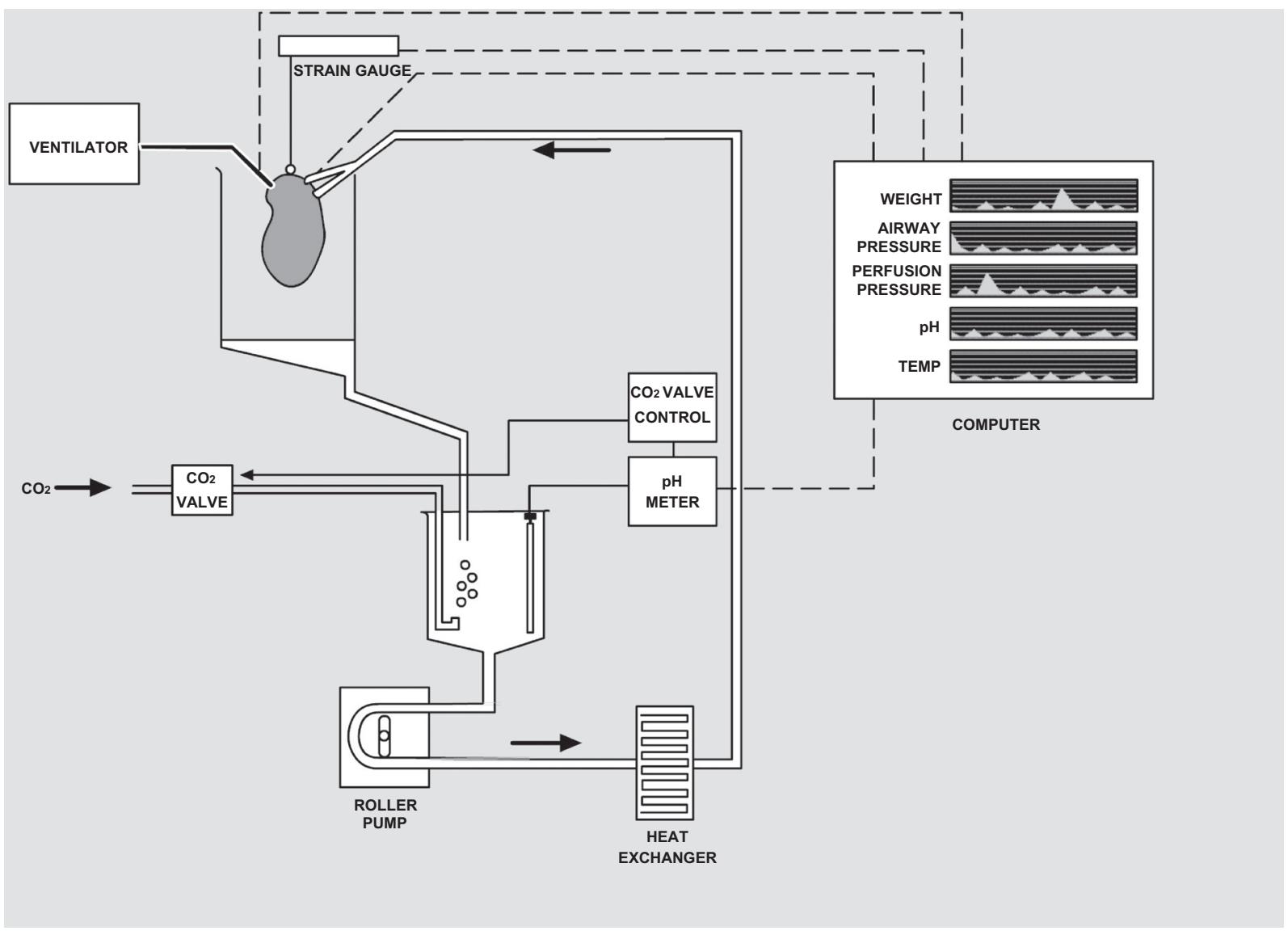

Figure I Perfusion-ventilation circuit for ex vivo isolated lung model. This diagram shows the lung attached via a cannula to the ventilator, seen on the left. A further cannula attaches the lung to the perfusion circuit, whereby oxygenated Krebs solution is passed from the reservoir, by a roller pump, via a heat exchanger to the lung. The $\mathrm{pH}$ of the Krebs solution is monitored and extra carbon dioxide $\left(\mathrm{CO}_{2}\right)$ is added as required. The $\mathrm{pH}$, weight, perfusion pressure, temperature and airway pressure are all measured and displayed on a computer screen, seen here on the right.

USA) and $\mathrm{pH}$ at 7.4 via a $\mathrm{pH}$ meter (Thermo Russell, Fife, $\mathrm{UK}$ ), which activated the supply of additional $\mathrm{CO}_{2}$ into the perfusate via a valve control, when the $\mathrm{pH}$ was greater than 7.4. The perfusion pressure, airway pressure and weight were continually recorded.

Once stable baseline airway and perfusion pressures were obtained the lungs were exposed to $\mathrm{KCl}(100 \mathrm{mM})$ and the maximum contraction was recorded. Cumulative additions of either testosterone $(1 \mathrm{nM}-100 \mu \mathrm{M})$ or ethanol vehicle ( maximum concentration $=0.1 \%$ ) were then performed. The system was then washed with 2 liters of fresh Krebs solution before the preparation was re-exposed to $\mathrm{KCl}(100 \mathrm{mM})$ and the alternative agent added.

\section{Materials and reagents}

Krebs bicarbonate solution consisted of $113.8 \mathrm{mM} \mathrm{NaCl}$, $4.7 \mathrm{mM} \mathrm{KCl}, 1.2 \mathrm{mM} \mathrm{MgSO}$, $25 \mathrm{mM} \mathrm{NaHCO}_{3}, 1.2 \mathrm{mM}$ $\mathrm{KH}_{2} \mathrm{PO}_{4}, 11.4 \mathrm{mM}$ glucose and $2.4 \mathrm{mM} \mathrm{CaCl}_{2}$ dissolved in distilled water. PSS consisted of $120 \mathrm{mM} \mathrm{NaCl}, 4.7 \mathrm{mM} \mathrm{KCl}$,

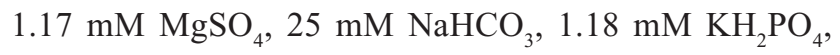
$5.5 \mathrm{mM}$ glucose, $2.5 \mathrm{mM} \mathrm{CaCl}_{2}$, and $26.9 \mu \mathrm{M}$ EDTA dissolved in distilled water. All other chemicals were obtained from Sigma, Poole, Dorset, UK. Testosterone and $\mathrm{U} 46619$ were dissolved in ethanol and $\mathrm{ACh}$ and $\mathrm{KCl}$ were dissolved in distilled water.

\section{Statistical analysis}

All valves are expressed as mean (SEM). Initial analysis examining whether there was a statistical difference between the response of vessels to testosterone versus ethanol, was made by Student's paired or unpaired t-test for parametric data. Subsequent analysis was then made between responses to testosterone between male and female preparations. In this set of analyses the dilator responses to testosterone are expressed as percentage reversal of the pre-contractile tone less the negligible vasoactive action of ethanol vehicle (always $<10 \%$ contraction/dilatation) and compared using ANOVA. In all cases $\mathrm{P}<0.05$ was considered statistically significant. 


\section{Results}

\section{Isolated human pulmonary arteries}

The basal characteristics of the pulmonary vessels studied in the Cambustion myograph is displayed in Table 1. No significant differences were observed in the patient age, vessel size, baseline tension or responsiveness between groups of preparations. Subsequent dilatory responses were consequently standardized by expression as percentage reversal of precontractile tone.

\section{Effect of testosterone}

The isolated human pulmonary arteries showed significant vasodilation compared to ethanol, reaching statistical significance at $30 \mu \mathrm{M}$ and $100 \mu \mathrm{M}$ (Figure 2).

\section{Effect of gender}

Pulmonary arteries obtained from male and female patients showed no significant difference in the magnitude of the response to testosterone (Figure 3).

\section{Isolated perfused human lungs}

The basal characteristics of the isolated perfused human lung preparations are displayed in Table 2. No significant differences were observed in the age, baseline pressure or responsiveness between groups of preparations.

\section{Effect of testosterone}

The vasodilator response to testosterone in the isolated perfused human lung preparations is displayed in Figure 4. This reached statistical significance at $100 \mu \mathrm{M}$. The response to testosterone was larger than that observed in the isolated vessels, as observed by comparison between Figures 2 and 4 (maximum change in tension in the isolated human pulmonary arteries $-24.9 \pm 2.2 \%$ versus $100 \pm 13.6 \%$, in isolated perused human lung samples, $\mathrm{P}<0.0001$ ).

\section{Effect of gender}

Isolated perfused human lung samples obtained from male and female patients showed no significant difference in the magnitude of the response to testosterone (Figure 5).

\section{Discussion}

The results of this study demonstrate for the first time that testosterone acts as an efficacious vasodilator in the human pulmonary circulation. Dilatation was observed following exposure to testosterone in isolated human pulmonary arteries and in isolated ventilated and perfused human lungs. Significant dilatation was observed at supraphysiological concentrations (normal range $8-30 \mathrm{nmol} / 1$ ), although marked vasodilatation was observed in all preparations at micromolar concentrations.

No significant difference in vasodilatation to testosterone was observed in pulmonary arteries obtained from male patients compared to those obtained from female patients (Figure 3). This finding was also seen in the isolated perfused lungs (Figure 5). The isolated perfused human lung studies, is the most representative of the in vivo situation, as the model contains both resistance vessels $<500 \mu \mathrm{m}$ in diameter and pulmonary veins. These resistance vessels are impossible to dissect for myography studies, however they are the main vessels governing pulmonary vascular tone. The pulmonary veins are also important as the venous circulation is sensitive to the vasodilator action of testosterone (Rowell et al 2003). This lack of a significant difference dependant upon gender in the isolated pulmonary vessels and the isolated perfused human lung studies is in contrast to the situation in the pulmonary vasculature of the rat where testosterone is reported to exhibit significantly greater dilatation in isolated pulmonary arteries obtained from males (English et al 2001). This may represent species variation in the effects of testosterone. Alternatively it may be a consequence of the difference in age. The tissue used in the present study was obtained from elderly patients, whereas the rat vessels were obtained from young sexually mature animals. We have previously reported that aging is associated with a decline in the vasodilator activity of testosterone in the male coronary circulation (English et al 2000b).

These data demonstrate that testosterone is an efficacious dilatory agent within the whole of the human pulmonary vasculature. Furthermore, they provide an insight into the

Table I The vessel characteristics used in this set of experiments, detailing the number of patients and their mean age, as well as the mean internal diameter of those vessels and their response to the vasocontractile agent U466I9 and vasodilator agent acetylcholine (ACh). Values expressed as mean (SEM)

\begin{tabular}{|c|c|c|c|c|c|c|}
\hline & $\begin{array}{l}\text { Number } \\
\text { of vessels }\end{array}$ & $\begin{array}{l}\text { Mean internal } \\
\text { diameter }(\mu \mathrm{m})\end{array}$ & $\begin{array}{l}\text { Mean patient } \\
\text { age (years) }\end{array}$ & $\begin{array}{l}\text { Number } \\
\text { of patients }\end{array}$ & $\begin{array}{l}\text { Mean contraction } \\
\text { to } 10 \mu \mathrm{m} U 46619(\mathrm{mN} / \mathrm{mm})\end{array}$ & $\begin{array}{l}\text { Mean dilatation to } \\
10 \mu \mathrm{m} \text { Ach (\% Relaxation) }\end{array}$ \\
\hline $\begin{array}{l}\text { Pulmonary } \\
\text { arteries - Male }\end{array}$ & 18 & $550(73)$ & $65(3)$ & 7 & $2.52(0.36)$ & $-14.6(4.7)$ \\
\hline $\begin{array}{l}\text { Pulmonary } \\
\text { arteries - Female }\end{array}$ & 14 & $54 \mid(42)$ & $56(7)$ & 6 & $2.38(0.39)$ & $-9.5(3.5)$ \\
\hline
\end{tabular}




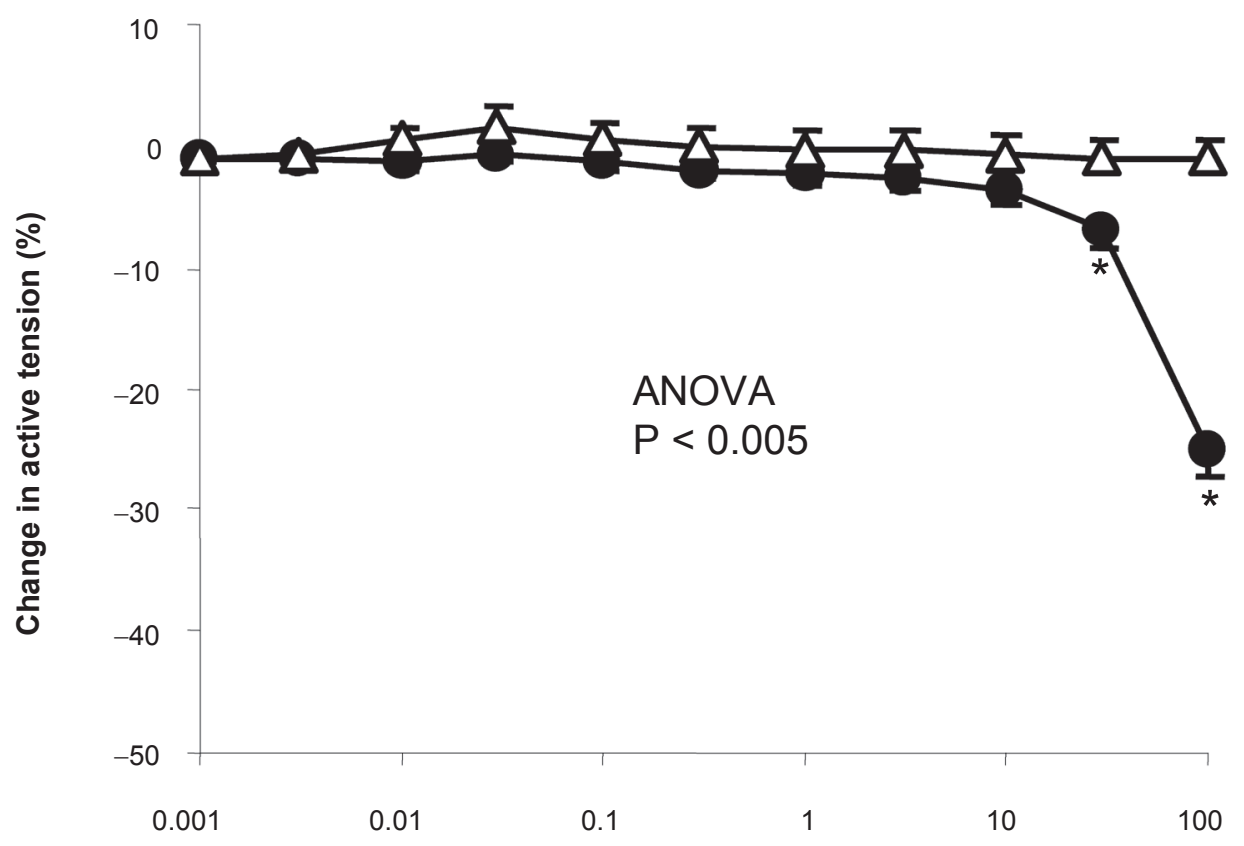

\section{Concentration of testosterone $(\mu \mathrm{M})$}

Figure 2 Concentration-response curve depicting the dilator response to testosterone $(\mathrm{Inm}-100 \mu \mathrm{M})$ in isolated human pulmonary arteries, maximally pre-constricted with U46619 (I $\mu \mathrm{M})$, studied in the Cambustion myograph. Data are expressed as mean change in active tension \pm SEM. Circles ( $\bullet$ ) represent vessels exposed to testosterone $(n=32)$, whilst triangles $(\Delta)$ represent vessels exposed to ethanol $(n=32)$. Significant vasodilatation compared to ethanol is seen at the last two doses of testosterone, $30 \mu m$ and $100 \mu \mathrm{m}$.

Note: ${ }^{\mathrm{P}}<0.05$ represents significant vasodilatation from ethanol vehicle via Student's t-test, following ANOVA.

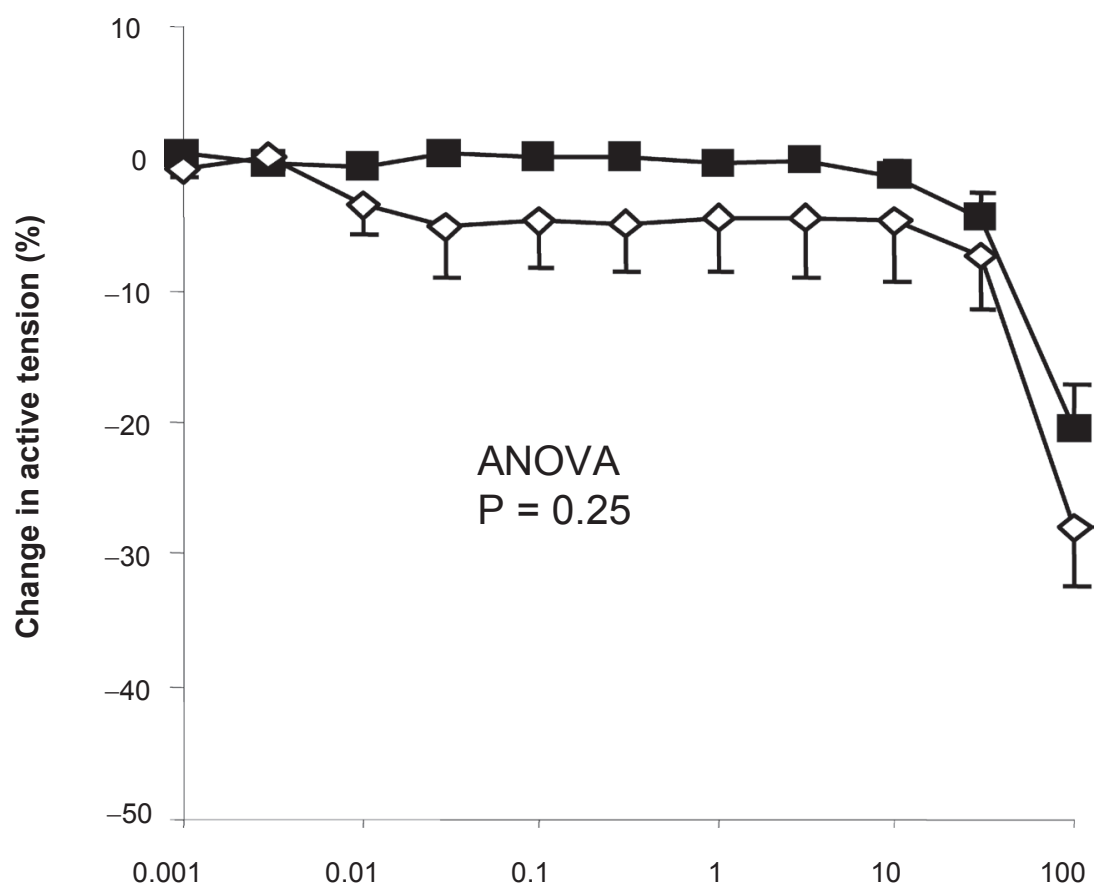

\section{Concentration of testosterone $(\mu \mathrm{M})$}

Figure 3 Concentration-response curve depicting the dilator response to testosterone $(\mathrm{Inm}-100 \mu \mathrm{M})$ in isolated pulmonary arteries, studied in the Cambustion myograph displayed as preparations obtained from male $(\boldsymbol{\square})(n=18)$ and female $(\diamond)(n=14)$ patients, maximally pre-constricted with U46619 $(I \mu M)$. Data are expressed as mean change in active tension (corrected for the negligible vasoactive effect of ethanol vehicle) \pm SEM. No significant difference was seen between vessels from male and female vessels on the response to testosterone. 
Table 2 The basal characteristics of the isolated human lung preparations. Values expressed as mean (SEM)

\begin{tabular}{|c|c|c|c|c|c|}
\hline & $\begin{array}{l}\text { Number } \\
\text { of lungs }\end{array}$ & $\begin{array}{l}\text { Number } \\
\text { of patients }\end{array}$ & Mean patient age (years) & Baseline pressure $(\mathrm{mmHg})$ & $\begin{array}{l}\text { Mean contraction to } 100 \mathrm{mM} \\
\mathrm{KCl}(\mathrm{mmHg})\end{array}$ \\
\hline $\begin{array}{l}\text { Isolated perfused } \\
\text { lung - Male }\end{array}$ & 6 & 6 & $62(7)$ & I7.4 (0.4) & $13.0(5.7)$ \\
\hline $\begin{array}{l}\text { Isolated perfused } \\
\text { lung - Female }\end{array}$ & 6 & 6 & $66(4)$ & I7.8 (0.4) & I $5.3(4.2)$ \\
\hline
\end{tabular}

vasodilator mechanism of action of testosterone within the human pulmonary vascular bed. It would appear that the mechanism of action is nongenomic in nature, since vasodilatation was observed within minutes of application of the hormone ( $23 \pm 3$ minutes in the IPHL model), rather then a prolonged time interval, which would be expected if binding to the androgen receptor and alteration of protein synthesis was occurring. This is consistent with previous studies undertaken in isolated rat pulmonary arteries, which suggest that testosterone elicits pulmonary vasodilatation via inhibition of voltage gated calcium channels (Jones et al 2002).

The results of the present study also support this mechanism of action in humans: The effect of testosterone in the isolated pulmonary arteries clearly depends upon the precontractile agonist used, with significantly more dilatation being observed in the IPHL experiments preconstricted with $\mathrm{KCl}$ compared to pulmonary vessels preconstricted with U46619. It has been shown that $\mathrm{KCl}$-induced vasoconstriction in similar isolated human pulmonary arteries occurs exclusively via extracellular calcium entry through VGCCs, whilst exposure to U46619 results in extracellular calcium entry through VGCC and also SOCCs, in approximately equal amounts (Hall et al 2004). Consequently if testosterone is only inhibiting the VGCCs and not SOCCs, as has been proposed in the rat pulmonary circulation (Jones et al 2002), the resulting dilatation in vessels preconstricted with U46619 would be expected to be approximately $50 \%$ less than in those preconstricted with $\mathrm{KCl}$. This was the case in these experiments, with Figure 2 showing a change in tension of $24.9 \pm 2.2 \%$ at the $100 \mu \mathrm{M}$ dose of testosterone in the isolated pulmonary arteries compared to

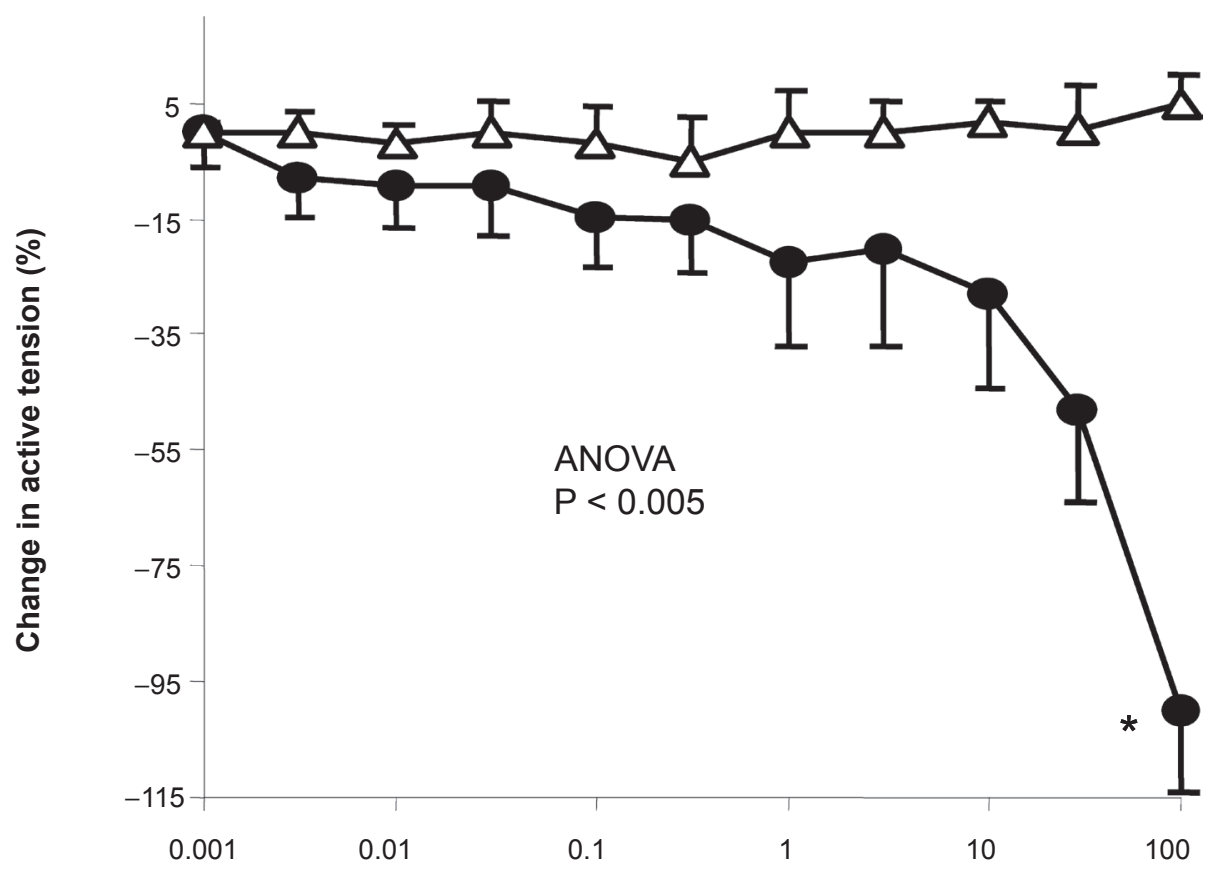

Concentration of testosterone $(\mu \mathrm{M})$

Figure 4 Concentration-response curve depicting the dilator response to testosterone $(\mathrm{Inm}-100 \mu \mathrm{M})$ in isolated perfused human lung maximally preconstricted with $\mathrm{KCL}$ $(100 \mathrm{mM})$. Data are expressed as mean change in active \pm SEM. Circles $(\bullet)$ represent vessels exposed to testosterone $(n=I 2)$, whilst triangles $(\Delta)$ represent vessels exposed to ethanol $(n=12)$.

Notes: ${ }^{*} \mathrm{P}<0.05$ represents significant vasodilatation from ethanol vehicle via Student's t-test, following ANOVA. 


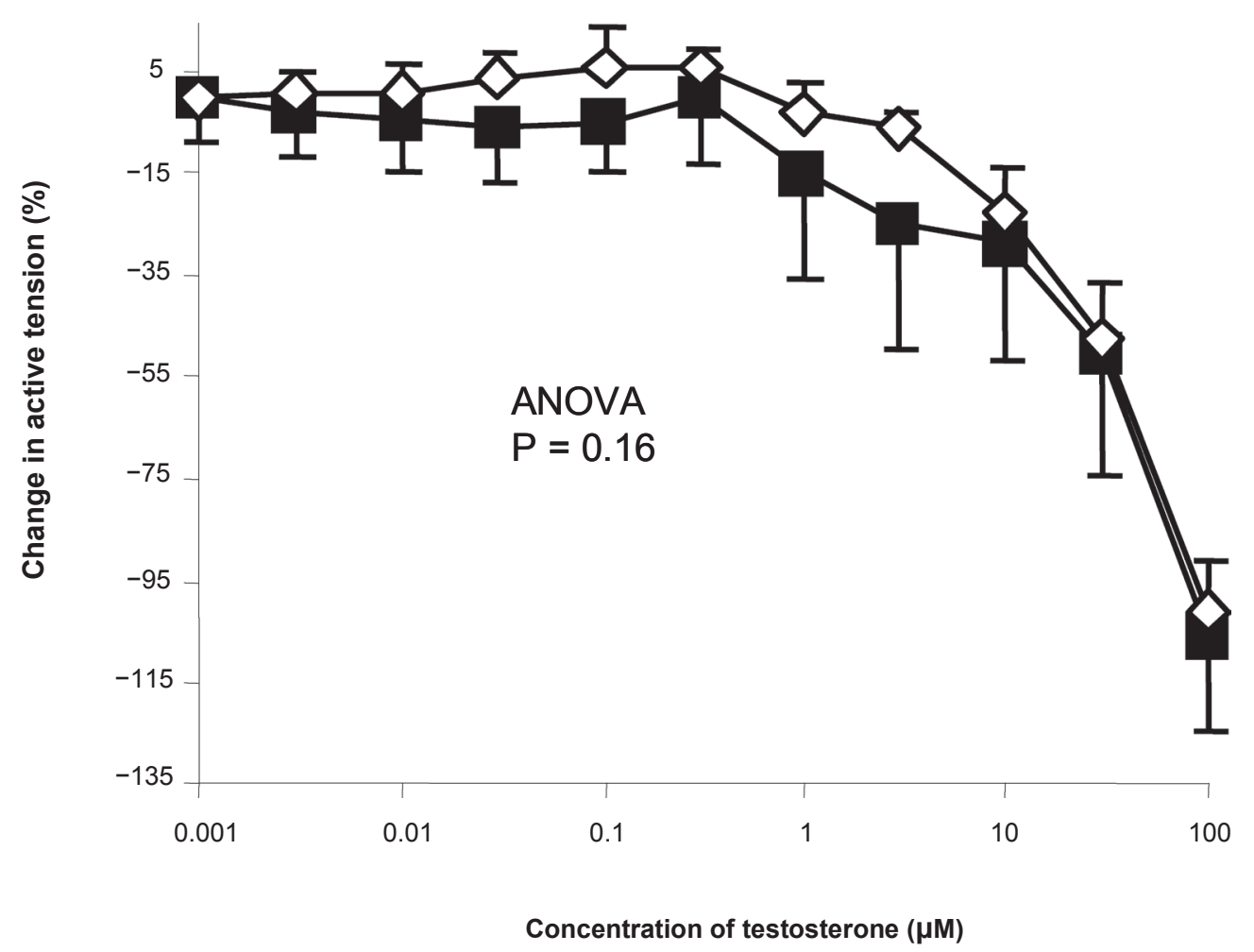

Figure 5 Concentration-response curve depicting the dilator response to testosterone ( $1 \mathrm{~nm}-100 \mu \mathrm{M})$ in isolated perfused human lung experiments, displayed as preparations obtained from male $(\nabla)(n=6)$ and female $(\diamond)(n=6)$ patients, maximally preconstricted with $\mathrm{KCl}(100 \mathrm{mM})$. Data are expressed as mean change in active tension (corrected for the negligible vasoactive effect of ethanol vehicle) \pm SEM. No significant difference was seen between vessels from male and female vessels on the response to testosterone.

$100 \pm 13.6 \%$ at the $100 \mu \mathrm{M}$ dose of testosterone in the isolated perfused human lung studies (Figure 4).

This vasodilator/calcium antagonistic activity of testosterone may allude to a new therapeutic opportunity for men with pulmonary hypertension. Calcium channel blockers, such as amlodipine, diltiazem, and nifedipine, have been used successfully in the treatment of pulmonary hypertension (Rubin et al 1983; Rich et al 1992; Woodmansey et al 1996) and as we have recently reported that testosterone acts like the calcium channel blocher nifedipine by inhibiting the L-type voltagegated calcium channels (VGCCs) (Scragg et al 2004; Hall et al 2006), therefore testosterone therapy may also be a potential treatment for male patients with pulmonary hypertension. The concentrations of testosterone required to produce vasodilatation in these in vitro preparations were supraphysiological, and therefore the applicability to patients may be questionable. However it has been shown that testosterone acts at physiological concentrations at the cell level (Scragg et al 2004; Hall et al 2006) and positive results have been seen with testosterone therapy in patients with angina (English et al 2000a) and heart failure (Pugh et al 2004; Malkin et al 2009), despite a similar discrepancy in the concentration required to induce dilatation in isolated rat coronary arteries (Jones et al 2004). Furthermore there is evidence that testosterone may be actively absorbed by the capillaries leading to much higher concentrations of testosterone at the capillary membrane than is measured by serum samples (Porto et al 1995). This discrepancy between the concentrations of chemicals required to produce effects in vivo and in vitro is also seen with others agents, for example the potassium channel opener chromakalin. This reduces systolic arterial pressure and systemic vascular resistance in vivo at concentrations of $2-3 \times 10^{-8} \mathrm{M}$ (Thomas et al 1990). In vitro these vasodilator effects are seen at $1 \times 10^{-6} \mathrm{M}$ to $1 \times 10^{-5}$ M (Bray et al 1991).

In summary, testosterone is an efficacious vasodilator in the human pulmonary vasculature and this is not modulated by patient sex. This vasodilator action suggests that testosterone therapy may be beneficial to male patients with $\mathrm{PAH}$, as reported in men with coronary artery disease (English et al 2000a) or congestive heart failure (Pugh et al 2004; Malkin et al 2009). Testosterone therapy unfortunately could not be offered to female patients, due to the secondary male sexual characteristics that may develop as a result of treatment. The mechanism of the vasodilator action of testosterone in rat pulmonary arteries is reported to be via calcium antagonism, specifically VGCCs (Jones et al 2002) however further 
experiments are required to confirm the mechanism in the human pulmonary circulation.

\section{Acknowledgments}

This project was funded by a project grant from Heart Research UK, formerly the National Heart Research Fund. The authors would like to thank Mr D Hopkinson, Mr S Billing, Mr G Rocco and Mr R Vaughan, consultant cardio-thoracic surgeons at the Northern General Hospital, Sheffield, UK, for kindly providing us access to their patients, and Dr Steve Gill, Dr Jane Wagstaff and Miss Stephanie Clark for their assistance in the identification and consenting of suitable patients and in collecting the resected tissue. The authors would like to thank Dr SK Suvarna, consultant pathologist at the Northern General Hospital, Sheffield, UK, for his advice and expertise in providing us with macroscopically normal lung tissue. The authors declare no competing or conflict of interest in this work.

\section{References}

Bennett RT, Jones RD, Morice AH, et al. 2004. Vasoconstrictive effects of endothelin-1, endothelin-3, and urotensin II in isolated perfused human lungs and isolated human pulmonary arteries. Thorax, 59:401-7.

Bjornsson J, Edwards WD. 1985. Primary Pulmonary-Hypertension - a Histopathologic Study of 80 Cases. Mayo Clin Proc, 60:16-25.

Bray K, Quast, U. 1991. Differences in K+ channels opened by cromokalin, acetylcholine and Substance $\mathrm{P}$ in rat aorta and porcine coronary artery. Br J Pharmacol, 102:585-94.

Dalonzo GE, Barst RJ, Ayres SM, et al. 1991. Survival in patients with primary pulmonary-hypertension - Results from a National Prospective Registry. Ann Intern Med, 115:343-9.

English KM, Steeds RP, Jones TH, et al. 2000a. Low-dose transdermal testosterone therapy improves angina threshold in men with chronic stable angina - A randomized, double-blind, placebo-controlled study. Circulation, 102:1906-11.

English KM, Jones RD, Jones TH, et al. 2000b. Aging reduces the responsiveness of coronary arteries from male Wistar rats to the vasodilatory action of testosterone. Clin Sci, 99:77-82.

English KM, Jones RD, Jones TH, et al. 2001. Gender differences in the vasomotor effects of different steroid hormones in rat pulmonary and coronary arteries. Horm Metab Res, 33:645-52.

Gibbs JSR, Higenbottam TW, Black C, et al. 2001. Recommendations on the management of pulmonary hypertension in clinical practice. Heart, 86:I1-I13.
Gonzales RJ, Walker BR, Kanagy NL. 2001. 17 beta-Estradiol increases nitric oxide-dependent dilation in rat pulmonary arteries and thoracic aorta. Am J Physiol Lung Cell Mol Physiol, 280:L555-4.

Hall J, Jones RD, Vaughan R, et al. 2004. Mechanisms of agonist-induced vasoconstriction in isolated human pulmonary arteries. British Pharmacological Society, 2:034.

Hall J, Jones RD, Jones TH, et al. 2006. Selective inhibition of L-type $\mathrm{Ca}^{2+}$ channels in A7r5 cells by physiological levels of testosterone. Endocrinology, 147:2675-80.

Jones RD, English KM, Pugh PJ, et al. 2002. Pulmonary vasodilatory action of testosterone: Evidence of a calcium antagonistic action. J Cardiovasc Pharmacol, 39:814-23.

Jones RD, English KM, Jones TH, et al. 2004. Testosterone-induced coronary vasodilatation occurs via a non-genomic mechanism: evidence of a direct calcium antagonism action. Clin Sci, 107:149-58.

Li HF, Zheng TZ, Li W, et al. 2001. Effect of progesterone on the contractile response of isolated pulmonary artery in rabbits. Can J Physiol Pharmacol, 79:545-50.

Malkin CJ, Jones TH, Channer KS. 2009. Testosterone in chronic heart failure. Front Horm Res, 37:183-96.

Pietra GG, Edwards WD, Kay JM, et al. 1989. Histopathology of primary pulmonary hypertension. A qualitative and quantitative study of pulmonary blood vessels from 58 patients in the National Heart, Lung, and Blood Institute, Primary Pulmonary Hypertension Registry. Circulation, 80:1198-206.

Porto CS, Lazari MFM, Abreu LC, et al. 1995. Receptors for androgen binding proteins: Internalisation and intracellular signalling. J Steroid Biochem Mol Biol, 53:561-5.

Pugh PJ, Jones RD, West JN, et al. 2004. Testosterone treatment for men with chronic heart failure. Heart, 90:446-7.

Rich S, Kaufmann E, Levy PS. 1992. The effect of high doses of calcium-channel blockers on survival in primary pulmonary hypertension. $N$ Engl J Med, 327:76-81.

Rowell KO, Jones RD, Pugh PJ, et al. 2003. Testosterone is an efficacious vasodilator in isolated human pulmonary and mesenteric arteries and veins. Heart, 89:A30.

Rubin LJ, Nicod P, Hillis LD, et al. 1983. Treatment of primary pulmonary hypertension with nifedipine. A hemodynamic and scintigraphic evaluation. Ann Intern Med, 99:433-8.

Runo JR, Loyd JE. 2003. Primary pulmonary hypertension. Lancet, 361:1533-44.

Scragg JL, Jones RD, Jones TH, et al. 2004. Testosterone is a potent inhibitor of L-type $\mathrm{Ca}^{2+}$ channels. Biochem Biophys Res Commun, 318:503-6.

Thomas P, Dixon MS, Winterton SJ, et al. 1990. Acute haemodynamic effects of cromakalin in patients with angina pectoris. $\mathrm{Br} \mathrm{J}$ Clin Pharmacol, 29:325-31.

Wagenvoort CA. 1980. Lung biopsy specimens in the evaluation of pulmonary vascular disease. Chest, 77:614-25.

Woodmansey PA, Otoole L, Channer KS, et al. 1996. Acute pulmonary vasodilatory properties of amlodipine in humans with pulmonary hypertension. Heart, 75:171-3. 